\title{
The climatic imprint of bimodal distributions in vegetation cover for western Africa
}

\author{
Zun Yin ${ }^{1}$, Stefan C. Dekker ${ }^{2}$, Bart J. J. M. van den Hurk ${ }^{1,3}$, and Henk A. Dijkstra ${ }^{1}$ \\ ${ }^{1}$ Institute for Marine and Atmospheric research Utrecht, Utrecht University, Utrecht, the Netherlands \\ ${ }^{2}$ Copernicus Institute of Sustainable Development, Utrecht University, Utrecht, the Netherlands \\ ${ }^{3}$ Royal Netherlands Meteorological Institute, De Bilt, the Netherlands
}

Correspondence to: Zun Yin (yinzun2000@gmail.com)

Received: 24 September 2015 - Published in Biogeosciences Discuss.: 13 November 2015

Revised: 12 May 2016 - Accepted: 18 May 2016 - Published: 8 June 2016

\begin{abstract}
Observed bimodal distributions of woody cover in western Africa provide evidence that alternative ecosystem states may exist under the same precipitation regimes. In this study, we show that bimodality can also be observed in mean annual shortwave radiation and above-ground biomass, which might closely relate to woody cover due to vegetationclimate interactions. Thus we expect that use of radiation and above-ground biomass enables us to distinguish the two modes of woody cover. However, through conditional histogram analysis, we find that the bimodality of woody cover still can exist under conditions of low mean annual shortwave radiation and low above-ground biomass. It suggests that this specific condition might play a key role in critical transitions between the two modes, while under other conditions no bimodality was found. Based on a land cover map in which anthropogenic land use was removed, six climatic indicators that represent water, energy, climate seasonality and waterradiation coupling are analysed to investigate the coexistence of these indicators with specific land cover types. From this analysis we find that the mean annual precipitation is not sufficient to predict potential land cover change. Indicators of climate seasonality are strongly related to the observed land cover type. However, these indicators cannot predict a stable forest state under the observed climatic conditions, in contrast to observed forest states. A new indicator (the normalized difference of precipitation) successfully expresses the stability of the precipitation regime and can improve the prediction accuracy of forest states. Next we evaluate land cover predictions based on different combinations of climatic indicators. Regions with high potential of land cover transitions are revealed. The results suggest that the tropical forest in
\end{abstract}

the Congo basin may be unstable and shows the possibility of decreasing significantly. An increase in the area covered by savanna and grass is possible, which coincides with the observed regreening of the Sahara.

\section{Introduction}

Precipitation is the primary constraint for the presence of woody vegetation in Africa. Although the mean annual rainfall determines the maximum woody cover (Bucini and Hanan, 2007; Good and Caylor, 2011), large variation in vegetation cover is observed across a broad range of rainfall bands (Sankaran et al., 2005). It suggests that the actual cover fraction is significantly influenced by other factors and increases the difficulty of projecting ecosystem responses to future climate change. Obviously only precipitation is not sufficient to interpret the dynamics of ecosystems. Explicit climate conditions and mechanisms should enhance our understanding of current and future woody cover distributions.

From satellite observations, Hirota et al. (2011) and Staver et al. (2011b) showed that the distribution of the tropical woody cover fraction was not unimodal. For a given mean annual precipitation $(\bar{P})$, a range of ecosystems including grass (no trees), savanna (sparse tree cover) and forest states are observed, suggesting that alternative stable states of vegetation may exist (Van Nes et al., 2012; Kéfi et al., 2016). The alternative stable states are caused by feedback mechanisms (Scheffer et al., 2001, 2009) due to the interactions between vegetation and its local climate (Rietkerk et al., 2004; Dekker et al., 2007; Dijkstra, 2011). Staver et al. (2011a) 
demonstrated that due to a positive fire feedback the savanna state can maintain in water sufficient areas. The positive fire feedback implies that fire will decrease woody cover and the burned area will be colonized by herbaceous plants relatively quickly, which in turn provide more fuel for fire in the next dry season. On the other hand, fire hardly occurs when woody cover exceeds $60 \%$ as the amount of fuel is limited (Roy et al., 2008). Trees then colonize spaces from grass and the high degree of woody cover can be kept. Simultaneously, if water supply by precipitation is not sufficient, high transpiration rates by forest can lead to more enhanced convective cloud cover than by savanna (Entekhabi et al., 1992; Dekker et al., 2007), which can reduce incoming shortwave radiation and avoid further water loss (Seneviratne et al., 2010). Consequently forest can keep a wet environment for a longer time. This cloud feedback plays an important role for the stability of the forest state, especially during drought conditions.

Although alternative stable states can lead to bimodality in woody cover, it can also be caused by discontinuities in environmental drivers or variation in for instance the growth rates of woody plants (Yin et al., 2014b). Thus a better understanding of the cause of the observed bimodality is needed, for instance to evaluate the resilience of the current ecosystem to climate variation (Scheffer et al., 2009) and to predict potential shift of vegetation states.

To address the proposed questions, we focus on feedback mechanisms that can explain the essential cause of the alternative stable states (Kéfi et al., 2016). Assuming that the observed bimodality is related to the alternative stable states, the proposed feedback mechanisms should exist. Consequently, bimodality should also be found in variables that interact in the feedback loops. For instance, the mean annual shortwave radiation $(\bar{R})$ is a key factor in the cloud feedback. High and low $\bar{R}$ are expected to associate with low and high woody cover respectively if the cloud feedback is significant. Thus also $\bar{R}$ should have a bimodal distribution, corresponding to the bimodality of woody cover. The existence of bimodality in specific variables is therefore an extra piece of evidence for the existence of alternative stable states. More importantly, these feedback-integrated variables indicate the strength of a specific feedback loop, through which we are able to assess the stability of the current ecosystem.

Via vegetation-climate feedbacks, vegetation states and climatic variables are clearly linked. Obviously, these interactions comprise a wider set of characteristics than just mean annual rainfall and woody cover. Seasonality of rainfall has a clear impact on the dynamics of soil water, and consequently available water, for vegetation (Good and Caylor, 2011; Staver et al., 2011b). To explore the effects of rainfall seasonality on current ecosystem states, scientists have made use of the length of the dry season (Staver et al., 2011b), entropy of the rainfall time series (Feng et al., 2013) and a seasonality index (Good and Caylor, 2011). Moreover, vegetation states can clearly be controlled by climatic factors other than precipitation; radiation and its seasonality also result in spatial and temporal growth patterns, particularly under energy limited evaporation regimes (Seneviratne et al., 2010). Ignoring these additional drivers in the coupled vegetation climate system may lead to an incomplete picture of the prevailing mechanisms, probably misinterpreting the detected areas of potential bistability.

In this paper we hypothesize that bimodality should not only be found in woody cover, but due to the strong climatevegetation interaction they should also be found in some related variables. Above-ground biomass $B$ (Hansen et al., 2003) and mean shortwave radiation $\bar{R}$ (Boone et al., 2009) are chosen to verify our hypothesis. $B$ can be seen as a proxy for the development age of woody plants. It is also a measure of the fire feedback (Mayer and Khalyani, 2011) as high fire frequency and severity can reduce woody biomass significantly and lead to low $B . \bar{R}$ is a climatic variable for estimating the strength of the cloud feedback. A low $\bar{R}$ is interpreted as an environment with a more uniformly distributed precipitation regime, where fire is rare and woody plants can extend their canopies to increase woody cover $W$. And high $W$ can in turn diminish $\bar{R}$ by affecting cloud cover through reinforcing evapotranspiration (Entekhabi et al., 1992). We first expect that the bimodality can be found in both $B$ and $\bar{R}$. Moreover, the mode of low $W$ in the bimodality is expected to match with low $B$ and high $\bar{R}$; and high $W$ is expected to match with high $B$ and low $\bar{R}$.

After the detection of areas with bimodal states in $B, W$ and $\bar{R}$, we use conditional histograms to attribute distributions of one quantity to other quantities. As such we create a predictive set of equations for $W$, driven by the climate data for diagnosing areas displaying potential bimodality in the vegetation states. By analysing observations of multiple climatic indicators and classified land cover types, we investigate different prediction accuracies of these climatic indicators to different land cover types. A new method is proposed to predict potential land cover by combining predictions of these climatic indicators. Then we readdress the spatial distribution of potential land cover types in western and central Africa to illustrate areas where land cover change might occur in response to changes in the driving climatic conditions.

\section{Data and analysis methods}

\subsection{Data}

The region of interest covers western Africa $\left(\left(20^{\circ} \mathrm{W}\right.\right.$, $\left.30^{\circ} \mathrm{E}\right) \times\left(5^{\circ} \mathrm{S}, 20^{\circ} \mathrm{N}\right)$, see Fig. 1a and b). The MODIS (Moderate Resolution Imaging Spectroradiometer) Vegetation Continuous Fields (VCF) product (MOD44B; Hansen et al., 2003) provides high-resolution $(500 \mathrm{~m})$ satellite retrieved woody cover $W$ averaged over the period October 2000 to December 2001. Four consecutive annual cycles (2000-2003) of above-ground biomass $B$ are taken from Baccini et al. (2008), with $1 \mathrm{~km}$ spatial resolution. This data 

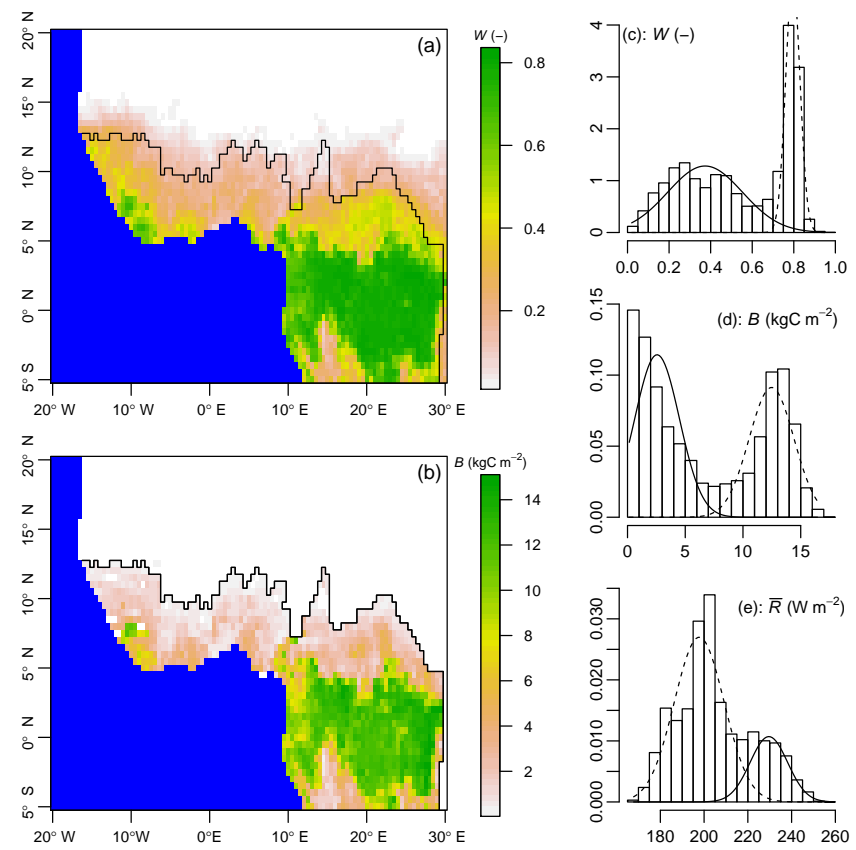

Figure 1. (a, b) Map of averaged woody cover $(W)$ and aboveground biomass $(B)$ in western Africa. In one climatic grid cell $\left(0.5^{\circ} \times 0.5^{\circ}\right)$, about 12321 data points of $W$ and $B$ (at $500 \mathrm{~m}$ resolution) are located. From this set 50 samples of $W$ and $B$ are taken randomly and averaged to estimate the mean value of $W$ and $B$ in each climatic grid cell. Note that the region covered by $B$-observations (denoted by black contour) is smaller than for $W$. Total rainfall in area covered by $W$-observations ranges between 212 and $4340 \mathrm{mmyr}^{-1}$, while $B$ data are only available where $\bar{P}>641 \mathrm{~mm} \mathrm{yr}^{-1}$. (c, d, e) Histograms of observed $W, B$ and $\bar{R}$ in the area where $B$-observation is available (the dark contour region in (b)). The $y$ axis is the density of the histograms. Solid and dashed curves represent savanna and forest states from the bimodality test respectively.

set only comprises biomass of woody plants, which is consistent with the woody cover data set. Six years (2002-2007) of precipitation $(P)$ and radiation $(R)$ data are calculated from a 3 hourly observation based data set intended for use as a climate forcing for the AMMA (African Monsoon Multidisciplinary Analysis) Land Surface Model Intercomparison Project (ALMIP; Boone et al., 2009). The spatial resolution is $0.5^{\circ}$.

Figure 1a and $\mathrm{b}$ shows grid-cell-averaged values of $W$ and $B$ from observations. The areal extent of $B$ is smaller than that of $W$, indicated by the dark contour line. In the overlapping region (where the conditional histogram analysis is carried out; see below), the mean annual precipitation $\bar{P}$ ranges from 950 to $1350 \mathrm{~mm} \mathrm{yr}^{-1}$ and the mean annual radiation $\bar{R}$ from 173 to $260 \mathrm{~W} \mathrm{~m}^{-2}$. Note that $\bar{P}$ ranges between 0 and $4340 \mathrm{~mm} \mathrm{yr}^{-1}$ when the entire western Africa is considered.

Anthropogenic land use is filtered from the data sets of $W$ and $B$, using data from the GlobCover project of the European Space Agency (ESA; http://due.esrin.esa.int/ page_globcover.php). This data set provides $300 \mathrm{~m}$ resolution global land cover data in 2005-2006 and 2009. As the 2009 version improves the classification of deforested patterns in tropical regions, it is used in this study.

\subsection{Conditional histograms}

The $B$ data set was resampled from $1 \mathrm{~km}$ to $500 \mathrm{~m}$ to adjust the $W$ data set by bilinear interpolation. In each $0.5^{\circ}$ grid cell of the climate data set, samples with zero $W$ or zero $B$ are filtered out first. A random subsample of 50 data points of $W$ and $B$ was assigned to every climate data grid cell. Next a statistical bimodality test was applied using the "flexmix" package (version 2.3-13) in $R$ (version 3.2.2; Grün and Leisch, 2007), evaluating the integrated completed likelihood (ICL) criterion (Biernacki et al., 2000). For various numbers of assumed data clusters the expectation maximization (EM) algorithm (Grün and Leisch, 2007) is used to determine the number of clusters best matching the observations (Biernacki et al., 2000). For cases where a bimodal distribution is found to provide the best data fit, the thresholds of the modes of $W, B$ and $\bar{R}$ are calculated. For instance, in a mixture of savanna and forest $(\mathrm{S}-\mathrm{F}), W_{1}$ indicates the low woody cover biome (the savanna state), while $W_{\mathrm{h}}$ indicates the forest state. Similarly, $B_{1}$ and $B_{\mathrm{h}}$ refer to the savanna and forest states respectively, while $\bar{R}_{\mathrm{h}}$ corresponds to the savanna state as high radiation levels are associated with a shorter rainfall season limiting the maximum potential $W$ (Good and Caylor, 2011). Consequently, $\bar{R}_{1}$ refers to the forest state.

Conditional histograms are compiled by selecting data of one distribution conditioned on whether or not the corresponding data in the other distribution belong to the savanna or forest categories. For instance, histograms of $W$ under both low and high conditions of $\bar{R}$ are constructed (that is, $\left(W \mid \bar{R}_{1}\right)$ and $\left(W \mid \bar{R}_{\mathrm{h}}\right)$ respectively), and subsequently it is tested whether the bimodality still exists.

Currently there is a contentious debate about the availability of the MODIS VCF product (Hansen et al., 2003) for multimodality research. The classification and regression tree (CART) method used for woody cover retrieval can lead to artificial bias, which is suggested to be the real reason for the observed multimodality (Hanan et al., 2014, 2015). However through MODIS data calibration, Staver and Hansen (2015) figure out that the bimodality of woody cover larger than $30 \%$ is not attributable to artificial bias. Similarly bias also exists in the above-ground biomass product (Baccini et al., 2008). The discontinuity in the satellite estimation is accompanied by the same discontinuity in validation data (Baccini et al., 2008), implying that the bimodality is not a reflection of the CART method (Hanan et al., 2015). Thus we conclude that both the woody cover and the above-ground biomass data sets are appropriate for a bimodality analysis of the coexistence of savanna and forest. More details are discussed in the Supplement. 


\subsection{Spatial classification of land cover}

The filtering of anthropogenic land use change is applied to all $W$ data for the entire western African area. For this, all vegetation cover data in every $0.5^{\circ}$ climatic grid cell (containing 12321 MODIS $500 \mathrm{~m} \times 500 \mathrm{~m}$ grid cells each) in this larger domain are processed, and GlobCover data points flagged as human activities are removed. These include the GlobCover classifications: post-flooding or irrigated croplands, rainfed croplands, mosaic cropland (50$70 \%) / v e g e t a t i o n$ (grassland, shrubland, forest) $(20-50 \%)$, water bodies, artificial surfaces and associated areas (urban areas $>50 \%$ ) and mosaic vegetation (grassland, shrubland, forest) (50-70\%)/cropland (20-50\%) (Bontemps et al., 2011). If the number of remaining $W$ samples in a climatic grid cell is less than 500, the entire grid cell is considered to be anthropogenic and no bimodality testing is applied. Classification into treeless, savanna and forest states is calculated using a bimodality test (Yin et al., 2014b). A positive detection of a bimodal distribution is followed by a check on the location of the peak values in the histogram to distinguish between grass-savanna (G-S) or savanna-forest (S-F) states. In addition, the relative proportion of the size of the two modes is calculated. We find that if the proportion of one mode is less than $5 \%$, large uncertainty will occur in the bimodality test. In cases with less than $5 \%$ in one mode, we assume an unimodal grid cell occupation by either grass, savanna or forest. More details are shown in the online Supplement.

\subsection{Climatology and potential shifts of ecosystem states}

The degree to which potential woody cover distributions can be explained by mean annual precipitation $(\bar{P})$ and rainfall seasonality has been addressed in various studies (Sankaran et al., 2005; Bucini and Hanan, 2007; Good and Caylor, 2011; Staver et al., 2011b; Hirota et al., 2011). In these studies, rainfall seasonality is characterized by different indicators (Good and Caylor, 2011; Staver et al., 2011b; Feng et al., 2013), which may lead to different sensitivities in the shift of climate regimes and ecosystem states. By including the precipitation seasonality in their analysis, Staver et al. (2011b) find a somewhat surprising potential bimodality in the heart of the Congo basin, in spite of a high precipitation amount even in the dry season of that region. The studies listed above did not include an analysis of climatic features that exclude the existence of a bistable vegetation regime, like seasonality patterns that do not allow fire or other processes that are essential for vegetation states.

We review a number of climatic indicators for expressing the variability of rainfall, and we explore the degree to which these indicators explain variations in ecosystem states. The relationships, trained with observed vegetation and climate characteristics, are used to determine the stability of woody cover and its sensitivity to potential shifts in climatic indicators in western Africa.

\subsection{Indicators for rainfall seasonality}

We use six climatic indicators to express the temporal dynamics of the water and energy cycle in western Africa. The mean annual precipitation $(\bar{P})$ represents the amount of water available to the land surface and is calculated from daily observations during the 6-year ALMIP period between 2002 and 2007 (Boone et al., 2009). The mean annual shortwave radiation $(\bar{R})$ describes the total amount of solar energy intercepted by the land surface and is calculated from the measured daily-averaged incoming shortwave radiation over the same 6-year period.

Two commonly used indicators of rainfall seasonality are the relative length of the dry season $\left(L_{\mathrm{D}}\right.$ in Staver et al., $2011 \mathrm{~b})$ and the entropy of relative monthly rainfall $\left(E_{\mathrm{p}}\right.$ in Feng et al., 2013). $L_{\mathrm{D}}$ is indicative for the length of the vegetation growing season, which in turn is related to the maximum potential woody cover. It is calculated by ranking the monthly rainfall $\left(p_{\mathrm{m}}\right)$ in ascending order. $L_{\mathrm{D}}$ is defined as the fraction of months with a cumulative rainfall amounts less than $10 \%$ of the total rainfall in the record.

$E_{\mathrm{p}}$ (Feng et al., 2013) is also determined using the monthly rainfall amount $\left(p_{\mathrm{m}}\right)$. For each year, the hydrological year is defined to start after the month with the minimum of $p_{\mathrm{m}}$. A climatological monthly rainfall amount $p_{\mathrm{m}}$ is derived by averaging the monthly rainfall in these hydrological years. When $q_{i}$ is the relative rainfall amount in a hydrological month $\left(p_{\mathrm{m}} / \bar{P}\right), E_{\mathrm{p}}$ can be obtained:

$E_{\mathrm{p}}=\sum_{i=1}^{12} q_{i} \log _{2}\left(\frac{q_{i}}{p_{\mathrm{h}}}\right)$,

where $p_{\mathrm{h}}(=1 / 12)$ is the uniform distribution of $p_{\mathrm{m}}$. Although the value of $E_{\mathrm{p}}$ varies greatly across climatic regimes (especially in monsoon areas in western Africa), the difference of $E_{\mathrm{p}}$ between the Sahara and tropical regions is very small, as rainfall seasonality is low in both regimes.

The final indicator is the normalized difference of precipitation $\left(\Delta_{\mathrm{p}}\right)$ :

$\Delta_{\mathrm{p}}=\frac{\max \left(\bar{p}_{\mathrm{m}}\right)-\min \left(\bar{p}_{\mathrm{m}}\right)}{\max \left(\bar{p}_{\mathrm{m}}\right)+\min \left(\bar{p}_{\mathrm{m}}\right)}$,

where $\max \left(\bar{p}_{\mathrm{m}}\right)$ and $\min \left(\bar{p}_{\mathrm{m}}\right)$ are maximum and minimum of climatologically averaged monthly precipitation respectively. A low value of $\Delta_{p}$ reflects tropical precipitation regimes, characterized by a small difference between minimum and maximum monthly precipitation and a high annual mean precipitation amount. The use of $\max \left(\bar{p}_{\mathrm{m}}\right)+\min \left(\bar{p}_{\mathrm{m}}\right)$ as a denominator in Eq. (2) limits the range of $\Delta_{p}$ in $[0,1]$. Compared with $L_{\mathrm{D}}$ and $E_{\mathrm{p}}, \Delta_{\mathrm{p}}$ is able to discriminate between low and wet precipitation regimes with a strong seasonality of both. 
Another indicator is the correlation coefficient of monthly mean precipitation and shortwave radiation across the number of years $\rho_{\bar{P}_{\mathrm{m}}}, \bar{R}_{\mathrm{m}}$, which accounts for seasonally varying magnitude of land-atmosphere coupling. The transpirationprecipitation feedback promotes cloud cover, which in turn blocks the incoming shortwave radiation and decreases $\rho_{\bar{P}_{\mathrm{m}}}, \bar{R}_{\mathrm{m}}$. Thus high negative correlation between $\bar{P}_{\mathrm{m}}$ and $\bar{R}_{\mathrm{m}}$ occurs in regions with strong land-atmosphere coupling (Koster et al., 2004).

\subsection{Relationship between climatic indicators and ecosystem states}

We analyse the relationship between climatic indicator (CI) and land cover (LC) for five different types: forest (F), grass $(\mathrm{G})$, savanna $(\mathrm{S})$ and coexisting grass-savanna $(\mathrm{G}-\mathrm{S})$ and savanna-forest $(\mathrm{S}-\mathrm{F})$. Note that bare ground is not considered in this analysis. For each of the six climatic indicators $\mathrm{CI}^{k}\left(k \in[1,6]\right.$ corresponding to $\bar{P}, \bar{R}, E_{\mathrm{p}}, \Delta_{\mathrm{p}}, L_{\mathrm{D}}$ and $\left.\rho_{\bar{P}_{\mathrm{m}}}, \bar{R}_{\mathrm{m}}\right), n$ equal width bins are defined, spanning the range of that indicator in our data set. $\mathrm{A} \mathrm{CI}^{k} \times \mathrm{LC}$ matrix, consisting of the number of grid cells $\left(v_{i, j}, i\right.$ is the number of bins and $j$ is LC) found in our data set of $n \mathrm{CI}^{k}$ ranges and five LC types, is constructed:

$\mathrm{CI}_{1}^{k}$
$\mathrm{CI}_{2}^{k}$
$\vdots$
$\mathrm{CI}_{n}^{k}$$\left(\begin{array}{ccccc}\mathrm{G} & \mathrm{G}-\mathrm{S} & \mathrm{S} & \mathrm{S}-\mathrm{F} & \mathrm{F} \\ v_{1,1} & v_{1,2} & v_{1,3} & v_{1,4} & v_{1,5} \\ v_{2,1} & v_{2,2} & v_{2,3} & v_{2,4} & v_{2,5} \\ \vdots & \vdots & \vdots & \vdots & \vdots \\ v_{n, 1} & v_{n, 2} & v_{n, 3} & v_{n, 4} & v_{n, 5}\end{array}\right)$

We test how for a given value of $\mathrm{CI}^{k}$, grid cells are distributed over the five LC types. For this we use the probability $q_{k, j}$, defined as follows:

$q_{k, j}=\frac{v_{i, j}}{\sum_{j=1}^{5} v_{i, j}}$,

where $k \in[1,6]$ represents the specific $\mathrm{CI}^{k}$, and $j$ is the $\mathrm{LC}$ type. $i$ indicates the band $\mathrm{CI}_{i}^{k}$ (Eq. 3) where the given $\mathrm{CI}^{k}$ value is located. With this probability matrix, a prediction of potential land cover in every grid cell is constructed by giving the value of a climatic indicator. For different types of climatic indicators these predictions will be different, as different sensitivities of LC types to different climatic indicators are found. For instance, by using the mean annual rainfall $(\bar{P})$, every land cover type in a given grid cell can be predicted with equal possibility $(20 \%$ for $\mathrm{G}, \mathrm{G}-\mathrm{S}, \mathrm{S}, \mathrm{S}-$ F, F), while $\Delta_{\mathrm{p}}$ indicates a different probability distribution ( $0 \%$ for $\mathrm{G}, \mathrm{G}-\mathrm{S}, \mathrm{S}, \mathrm{S}-\mathrm{F}$ and $100 \%$ for $\mathrm{F}$ ). To evaluate the predicted uncertainty of each climatic indicator to climate regimes, we define an entropy-like quantity $w_{k}$ :

$w_{k}=-\sum_{j=1}^{5} q_{k, j} \log _{2} q_{k, j}$.
Note that both $q_{k, j}$ and $w_{k}$ are grid cell dependent. Each grid cell has its own $q_{k, j}$ and $w_{k}$. So do variables which appear in Sect. 2.7.

\subsection{Predicted land cover types by climatic indicators}

The probability $q_{k, j}$ and uncertainty index $w_{k}$ can be used to predict the potential land cover for a given CI-combination. The two-step prediction procedure first redistributes the probability of mixed vegetation states $(\mathrm{G}-\mathrm{S}$ and $\mathrm{S}-\mathrm{F})$ over uniform vegetation probabilities $c_{k, \mathrm{~g}}, c_{k, \mathrm{~s}}$ and $c_{k, \mathrm{f}}$ for grass, savanna and forest respectively:

$$
\begin{aligned}
c_{k, \mathrm{~g}} & =q_{k, 1}+\frac{1}{2} q_{k, 2} \\
c_{k, \mathrm{~s}} & =\frac{1}{2} q_{k, 2}+q_{k, 3}+\frac{1}{2} q_{k, 4} \\
c_{k, \mathrm{f}} & =\frac{1}{2} q_{k, 4}+q_{k, 5} .
\end{aligned}
$$

In the second step the weighted mean of $c_{\mathrm{g}}, c_{\mathrm{s}}$ and $c_{\mathrm{f}}$ is calculated. For $c_{\mathrm{g}}$ this is the following:

$c_{\mathrm{g}}=\frac{\sum \frac{1}{w_{k}} c_{k, \mathrm{~g}}}{\sum \frac{1}{w_{k}}}$,

where the weights $w_{k}$ are taken as the uncertainty index of $\mathrm{CI}^{k}$ (Eq. 5). For $w_{k}=0(100 \%$ probability for a given vegetation structure) a low value $\left(10^{-3}\right)$ is chosen. Similar equations exist for savanna and forest.

From Eqs. (4), (6) and (7), we can find that $c_{\mathrm{g}}+c_{\mathrm{s}}+c_{\mathrm{f}}=1$. A probability exceeding $90 \%$ for a certain land cover type is considered a stable, unimodal vegetation structure. A probability less than $90 \%$ but exceeding $50 \%$ is considered to be an unstable ecosystem dominated by a single land cover type. Coexistence of grass, savanna and forest (each having considerable cover fractions) is found to be rare. As a result, the vegetation structure in western Africa can be classified by seven types: stable grass $\left(G_{s}\right)$, savanna $\left(S_{S}\right)$ and forest $\left(F_{S}\right)$; and bimodal types dominated by grass $\left(G_{b}\right)$, savanna $\left(S_{b}\right)$ and forest $\left(\mathrm{F}_{\mathrm{b}}\right)$, where the bimodal structure dominated by savanna includes two cases: G-S and S-F.

\subsection{Difference between observed and predicted land cover types}

To evaluate the stability and potential transition of current land cover in western Africa, we compare the predicted potential land cover with the observed land cover classification (Sect. 2.3). In this exercise the prediction uses the combination of climatic indicators $\bar{P}, L_{\mathrm{D}}$ and $\Delta_{\mathrm{p}}$, and the comparison comprises each land cover type $(\mathrm{G}, \mathrm{S}$ and $\mathrm{F})$ individually. For grass, $\mathrm{G}$ and $\mathrm{G}-\mathrm{S}$ are combined as grass in the observation, while predicted stable and grass-dominated vegetation types are similarly combined into a single grass category. By comparing the predicted and observed grass cover distributions we can distinguish three situations: 

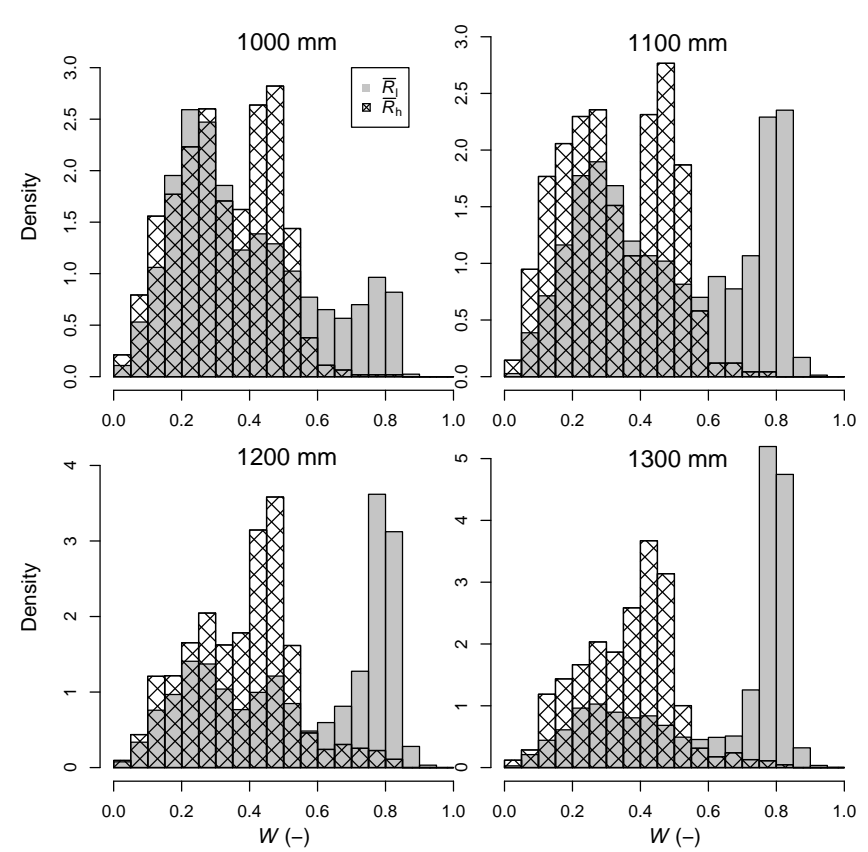

Figure 2. Histograms of observed woody cover for different categories of mean annual radiation $\bar{R}$, being $\bar{R}_{1}\left(<220 \mathrm{~W} \mathrm{~m}^{-2}\right.$, grey bars) and $\bar{R}_{\mathrm{h}}$ (>220 $\mathrm{W} \mathrm{m}^{-2}$, shaded bars). Panels represent samples taken under different total precipitation regimes.

1. Area currently covered by grass with predicted grass cover.

2. Area currently covered by grass with other predicted cover types.

3. Area currently covered by other types with predicted grass cover.

The same method is applied for savanna and forest. Note that G-S in the observation is shared by grass and savanna, while $\mathrm{S}-\mathrm{F}$ is shared by savanna and forest. This overlap has no significant effect on the analysis in principle.

\section{Results}

\subsection{Conditional histograms}

Figure 1c-e show the histograms of observed woody vegetation cover $W$, above-ground biomass $B$ and mean annual radiation $\bar{R}$ for the research area after filtering the anthropogenic land use out of the data. The bimodal distribution of $W$ and $B$ are clearly illustrated. Related bimodality analyses are implemented by Hirota et al. (2011) and Yin et al. (2014b) respectively. In the online Supplement we provide the evaluation of potential classes of $\bar{R}$. Based on the ICL and the density distributions of $\bar{R}$ under different $\bar{P}$ bands, two classes are determined as the best fit. A clear threshold between the savanna and forest states is found for $W(0.6), B$

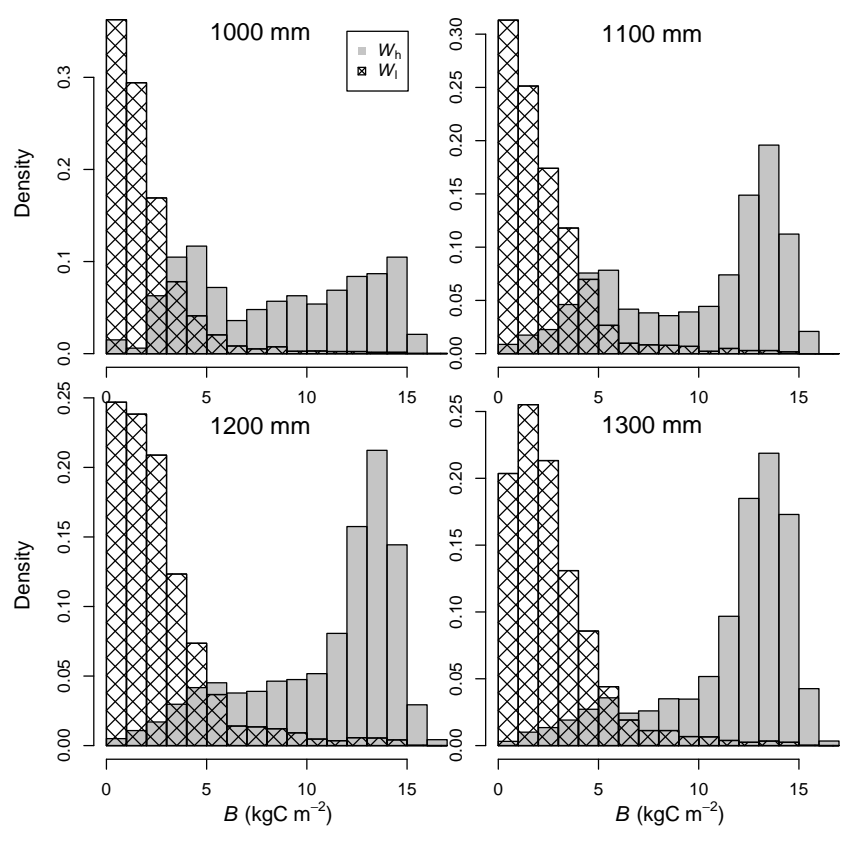

Figure 3. Histograms of above-ground biomass $B$ conditioned on woody cover $W_{1}\left(<0.6\right.$, shaded bars) and $W_{\mathrm{h}}$ ( $>0.6$, grey bars) under different precipitation regimes.

$\left(7 \mathrm{~kg} \mathrm{C} \mathrm{m}^{-2}\right)$ and $\bar{R}\left(220 \mathrm{~W} \mathrm{~m}^{-2}\right)$. Low $\bar{R}$ is generally associated with forest, while high $\bar{R}$ corresponds to the savanna state.

Based on the detected thresholds while including the whole research area in the analysis, we apply the conditional histogram method (Sect. 2.2) after stratifying the data into different $\bar{P}$ regimes $(1000 \pm 50,1100 \pm 50,1200 \pm 50$ and $1300 \pm 50 \mathrm{~mm} \mathrm{yr}^{-1}$ ). Figure 2 shows these conditional histograms of $W$ under fixed $\bar{R}$ intervals for the four precipitation regimes. The histograms $\left(W \mid \bar{R}_{\mathrm{h}}\right)$ successfully classify all data that obey the calculated threshold $(<0.6)$ for all four precipitation bands. This implies that under high radiation only low $W$ is found. In contrast, the histograms $\left(W \mid \bar{R}_{1}\right)$ are bimodal, indicating that alternative states coexist under low $\bar{R}$ conditions. The distribution of $W$ samples over $W_{1}$ and $W_{\mathrm{h}}$ is listed in Table 1. For all four precipitation regimes at least $94 \%$ of the data with $\bar{R}>220 \mathrm{~W} \mathrm{~m}^{-2}$ have a low $W(<0.6)$. For the low $\bar{R}$ class, however, only 19 to $62 \%$ of the $W$ data correspond to the high $W$ class.

Figure 3 shows the histograms of $B$ conditioned on the $W$ class. The histograms $\left(B \mid W_{1}\right)$ successfully classify all data below the threshold $B<7 \mathrm{~kg} \mathrm{C} \mathrm{m}^{-2}$. Again, at least $94 \%$ of all data with a low $W(<0.6)$ are associated with low $B$ (Table 1). However, for $\left(B \mid W_{\mathrm{h}}\right)$ a bimodal distribution is found, indicating that two $B$ modes exist with low $W$. Only 55 to $78 \%$ of the high $B$ data are associated with $W_{\mathrm{h}}$.

Table 2 summarizes the results. We found that the $W$ state can be determined under two conditions: (1) low $\bar{R}$ and high $B$, (2) high $\bar{R}$ and low $B$. The only regime where a bimodal- 
Table 1. Percentage of woody cover fraction $W$ and above-ground biomass $B$ falling into different $\bar{R}$ and $W$ categories respectively, being high radiation $\left(\bar{R}_{\mathrm{h}}, \bar{R}>220 \mathrm{~W} \mathrm{~m}^{-2}\right)$ and low radiation $\left(\bar{R}_{1}\right)$. High and low values of $W$ (higher or lower than 0.6$)$ are denoted by $W_{\mathrm{h}}$ and $W_{1}$, while biomass is categorized into high $\left(B_{\mathrm{h}}\right)$ and low $\left(B_{1}\right)$ values by taking $7 \mathrm{~kg} \mathrm{~m}^{-2}$ as threshold.

\begin{tabular}{lrrrrr}
\hline Conditions & Expected state & $1000 \mathrm{~mm}$ & $1100 \mathrm{~mm}$ & $1200 \mathrm{~mm}$ & $1300 \mathrm{~mm}$ \\
\hline $\bar{R}_{\mathrm{h}}$ & $W<0.6$ & 98.55 & 98.01 & 94.21 & 96.33 \\
$\bar{R}_{1}$ & $W>0.6$ & 18.54 & 37.68 & 62.84 & 48.32 \\
\hline$W_{1}$ & $B<7 \mathrm{kgC} \mathrm{m}^{-2}$ & 97.88 & 96.75 & 94.83 & 95.96 \\
$W_{\mathrm{h}}$ & $B>7 \mathrm{kgC} \mathrm{m}^{-2}$ & 55.91 & 68.02 & 78.91 & 78.91 \\
\hline
\end{tabular}

Table 2. Woody cover states determined by radiation $(\bar{R})$ and biomass $(B)$ states. Bimodality is considered to be a coexistence of savanna and forest states.

\begin{tabular}{lll}
\hline & Low $B$ & High $B$ \\
\hline Low $\bar{R}$ & Bimodality & High $W$ \\
High $\bar{R}$ & Low $W$ & N/A \\
\hline
\end{tabular}

ity is found is the combination of low $B$ and low $\bar{R}$. In the study area, a combination of high $B$ and high $\bar{R}$ did not occur.

\subsection{Spatial patterns of bimodal regimes}

We analysed all natural $W$ samples and applied the bimodality test on each climatic grid cell (Sect. 2.3). In Fig. 4a, western Africa is classified into six different $W$ classes using thresholds of $0,0.1$ and 0.6 to separate the unimodal classes: bare soil (B, $W=0$ ), grass (G, $0<W<0.1$ ), savanna (S, $0.1<W<0.6)$ and forest (F, $W>0.6)$. If a bimodal distribution was found, it was classified as either grass-savanna (G-S) or savanna-forest (S-F) depending on the location of the individual peaks. Figure 4a reveals that bimodal distributions only occur in the transition zones between unimodal land cover types. The coexistence of savanna and forest is only found in the south of Liberia and Ghana as well as in the Congo basin. In the Congo basin, the tropical forest is surrounded by the bimodal savanna-forest states.

To demonstrate the relations between land cover types and climate forcing, we distinguished between unimodal and bimodal cells in a $\bar{P}-\bar{R}$ scatter plot (Fig. $4 \mathrm{~b}$ and c). For a given $\bar{P}$, different unimodal or bimodal classes can be found, while $\bar{R}$ appears to be a better discriminator between the different classes.
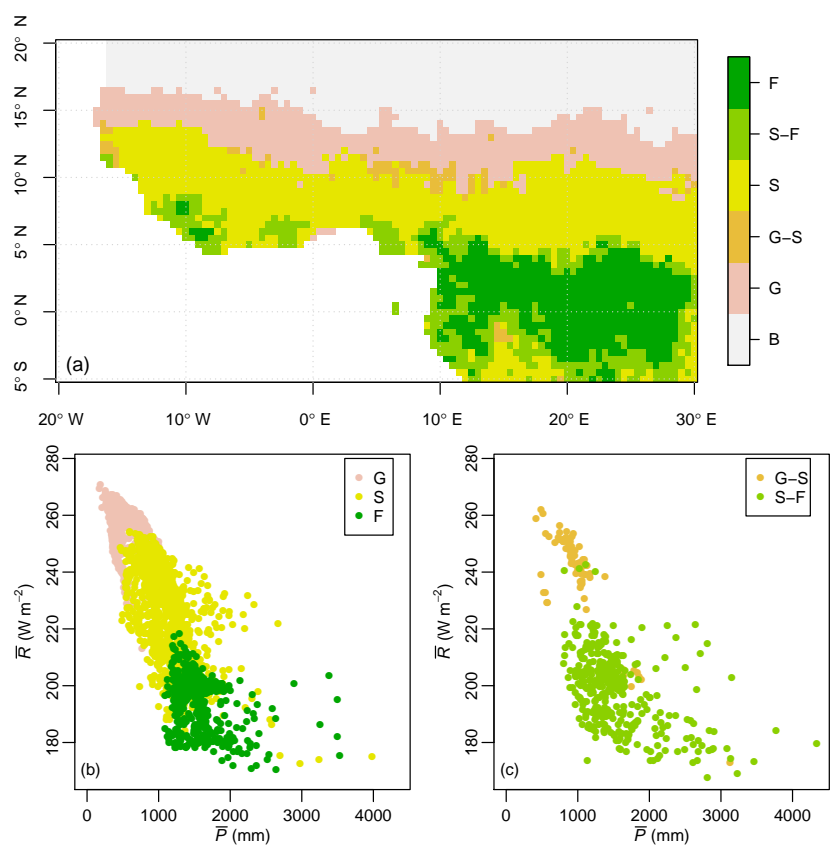

Figure 4. (a) Bimodality classification of woody cover in western Africa according to the integrated completed likelihood (ICL) criterion in the bimodality test. $(\mathbf{b}, \mathbf{c})$ Classification of mean annual precipitation $\bar{P}$ vs. mean annual radiation $\bar{R}$ based on Fig. 4a. B: bare soil. G: grass. G-S: grass-savanna. S: savanna. S-F: savannaforest. F: forest.

\subsection{Sensitivity of land cover types to climatic indicators}

The six climatic indicators (CI, Sect. 2.5) are calculated from the ALMIP climate data and stratified by land cover type (LC) as shown in Fig. 5. $\bar{P}$ (top left panel of Fig. 5) increases with an LC shift from $G$ to $F$, suggesting that precipitation is the main driver of LC. However, the response of different LC types shows a large mutual overlap, implying that with a given $\bar{P}$ multiple LC states can exist. Precipitation is a poor predictor for LC. The precipitation range where LC overlap occurs reflects the bimodality regime found by $\bar{P}$.

For $\bar{R}$ a negative relation with the woody cover fraction (from $\mathrm{G}$ to $\mathrm{F}$ ) is shown. $\bar{R}$ shows stronger sensitivity to the LC type than $\bar{P}$. Both $\mathrm{G}$ and $\mathrm{G}-\mathrm{S}$ are found for $\bar{R}$ exceeding 


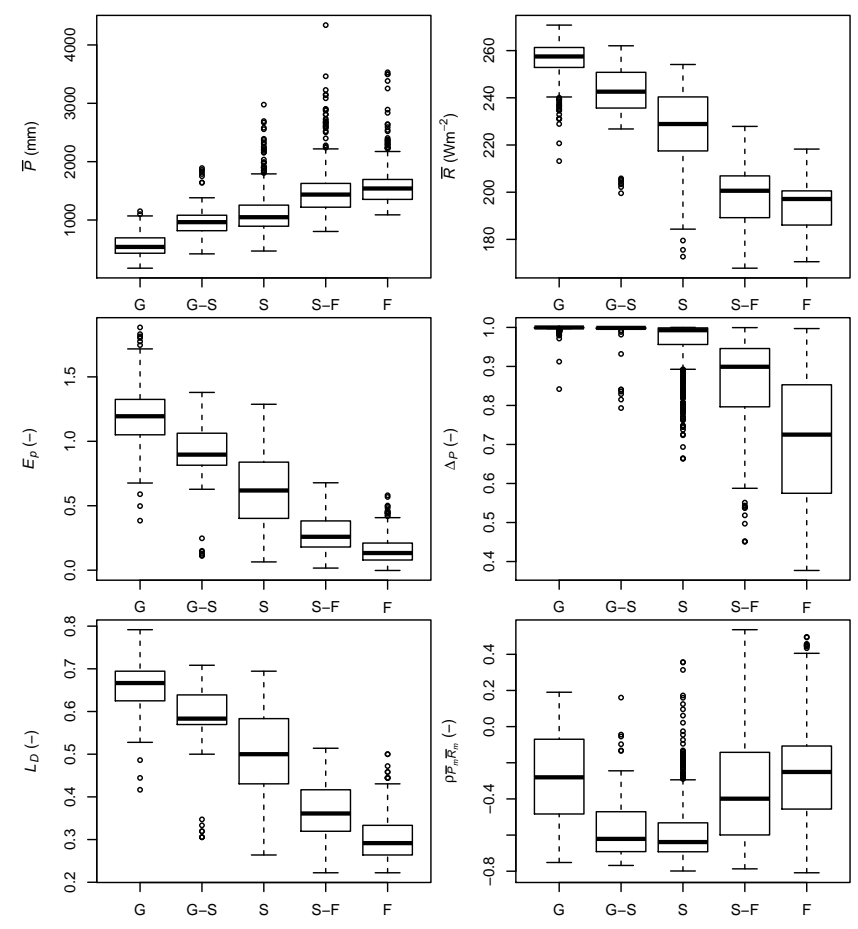

Figure 5. Box plot of six climatic indicators versus land cover types. $\bar{P}$ is mean annual precipitation, $\bar{R}$ is mean annual shortwave radiation, $E_{\mathrm{p}}$ is entropy of relative monthly precipitation, $\Delta_{\mathrm{p}}$ is normalized difference of averaged monthly precipitation, $L_{\mathrm{D}}$ is the maximum length of the dry season and $\rho_{\bar{P}_{\mathrm{m}}} \bar{R}_{\mathrm{m}}$ is correlation coefficient of monthly precipitation and monthly radiation.

$240 \mathrm{~W} \mathrm{~m}^{-2}$. For higher $\bar{R}\left(>262 \mathrm{~W} \mathrm{~m}^{-2}\right.$ ) only $\mathrm{G}$ is found, suggesting that high $\bar{R}$ is a necessary condition for stable G. A LC type consisting of S is found in a narrow window $\left(218<\bar{R}<238 \mathrm{~W} \mathrm{~m}^{-2}\right)$, implying that the savanna state is very stable in this range of $\bar{R}$. Some samples of G and G-S are also found in this range. However, they are in the tail of the specific distributions. $\mathrm{F}$ is found when $\bar{R}<228 \mathrm{~W} \mathrm{~m}^{-2}$, which contains the LC type S-F as well. As shown in Table 2, a low value of $\bar{R}$ is necessary but not exclusive for finding $\mathrm{F}$.

The covariation between LC and $E_{\mathrm{p}}$ is similar to the pattern shown for $\bar{R}$. However the range of $E_{\mathrm{p}}$ where grass is found is larger than the range occupied by forest. $E_{\mathrm{p}}>1.3$ is sufficient to predict the existence of grassland, which is thus a good climatic indicator for G. Both $E_{\mathrm{p}}$ and $\bar{R}$ focus on the detection of a seasonality of the forcing. However, they are not sufficient to predict a stable forest state. For instance, in spite of a strong seasonality in precipitation, if the amount of precipitation during the dry season is high enough to prevent fire occurrence, a stable F state can exist.

To distinguish the forest state from other LC types, we analyse the covariation between the normalized difference of precipitation $\left(\Delta_{\mathrm{p}}\right.$, Eq. 2) and LC. $\Delta_{\mathrm{p}}=1$ occurs when $\max \left(\bar{p}_{\mathrm{m}}\right) \gg \min \left(\bar{p}_{\mathrm{m}}\right)$ or $\min \left(\bar{p}_{\mathrm{m}}\right)=0$. A low value of $\Delta_{\mathrm{p}}$ requires a small seasonality in combination with a high value of minimum $\bar{p}_{\mathrm{m}}$. This quantity successfully segregates the range of climate regimes according to rainfall seasonality, amplified in a regime with a high precipitation amount. The results (middle right panel of Fig. 5) illustrate a successful introduction of new piece of information to the previously discussed climate indicators. $\mathrm{G}$ and $\mathrm{G}-\mathrm{S}$ are dominant for a specific value of $\Delta_{\mathrm{p}}$. A shift from grass to forest is accompanied by a strong decrease of $\Delta_{\mathrm{p}}$. For $\Delta_{\mathrm{p}}<0.90$, forest will surely be present and very stable for $\Delta_{\mathrm{p}}<0.59$, which provides a sufficient diagnostic of the occurrence of forest.

The length of the dry season $\left(L_{\mathrm{D}}\right.$, Fig. 5$)$ is another indicator expressing the climate seasonality. Although $L_{\mathrm{D}}$ is defined differently from $E_{\mathrm{p}}$, their results are similar.

The $\rho_{\bar{P}_{\mathrm{m}}}, \bar{R}_{\mathrm{m}}$ represents the coupling between monthly precipitation and radiation, which is predominantly negative (Fig. 5). The observed range of $\rho_{\bar{P}_{\mathrm{m}}}, \bar{R}_{\mathrm{m}}$ is between -0.81 and 0.54 . G, G-S, S-F and $\mathrm{F}$ are all found in large ranges of $\rho_{\bar{P}_{\mathrm{m}}, \bar{R}_{\mathrm{m}}}$-values, which complicates its use as LC predictor. Detection of savanna vegetation types could be linked to its dominant coexistence with negative values of $\rho_{\bar{P}_{\mathrm{m}}, \bar{R}_{\mathrm{m}}}$ meaning that savanna apparently requires an environment with a strong rainfall-radiation coupling, although its distribution has a fairly long tail.

Each of the climatic indicators does give useful information about the vegetation states, but they are not mutually statistically independent. Figure 6 shows the correlations between all climatic indicators. The highest correlation is found between $E_{\mathrm{p}}$ and $L_{\mathrm{D}}$, demonstrating that the prediction ability of the $E_{\mathrm{p}}$ is equivalent to that of the $L_{\mathrm{D}} . \bar{R}$ is highly correlated with both $E_{\mathrm{p}}$ and $L_{\mathrm{D}}$, since rainfall is strongly correlated to the downward radiation flux. The $\bar{P}$ is highly correlated with $\bar{R}, E_{\mathrm{p}}$ and $L_{\mathrm{D}}$, but is not a good discriminator for $\mathrm{LC}$ due to the large overlapping $\mathrm{LC}$ regimes for a given precipitation amount (Fig. 5). $\Delta_{\mathrm{p}}$ behaves similarly to $\bar{P}$, having a high correlation with $E_{\mathrm{p}}$ and $L_{\mathrm{D}}$. However, $\Delta_{\mathrm{p}}$ provides new information compared to the other climatic indicators, shown by the scatter plot of $E_{\mathrm{p}}$ vs. $\Delta_{\mathrm{p}}$ (row 4, column 3 in Fig. 6). $E_{\mathrm{p}}$ can distinguish grass from other LCs, but this is not true for $\mathrm{S}, \mathrm{F}$ and $\mathrm{S}-\mathrm{F}$, which show great overlapping regions. In contrast, $\Delta_{\mathrm{p}}$ is able to detect the differences between these LCs.

$\rho_{\bar{P}_{\mathrm{m}}, \bar{R}_{\mathrm{m}}}$ is fairly independent from other climatic indicators. The scatter plots between $\rho_{\bar{P}_{\mathrm{m}}}, \bar{R}_{\mathrm{m}}$ and other climatic indicators confirm the negative relation between rainfall and radiation, but quite different values of $\rho_{\bar{P}_{\mathrm{m}}}, \bar{R}_{\mathrm{m}}$ are shown for different land cover types. The $U$-shaped curves (the last row of Fig. 6) indicate that the strongest rainfall-radiation coupling is apparent for the savanna region. The tails of this distribution are populated by grass (dry climate) and forest (wet climate) where the correlation between rainfall and radiation is weaker.

Figure 7 illustrates the spatial distribution of the uncertainty index ( $w_{k}$ defined in Eq. 5) of six climatic indicators in our analysis domain. In two regions $\bar{P}$ provides LC 


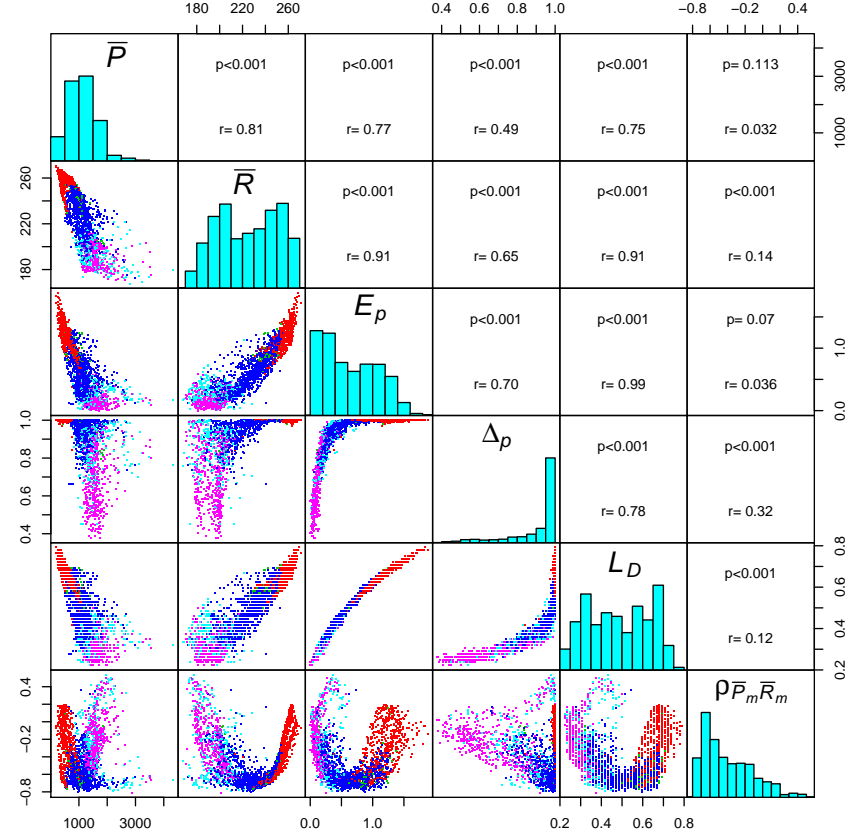

Figure 6. Correlation matrix of the six climatic indicators: $r$ is the correlation coefficient and $p$ is the $p$ value. Woody cover samples are coloured based on land cover types: red is $\mathrm{G}$, blue is $\mathrm{S}$, magenta is F, green is $\mathrm{G}-\mathrm{S}$ and cyan is $\mathrm{S}-\mathrm{F}$.

predictions with high confidence (Fig. 7a). In the Sahara this is obviously related to the stationary low precipitation regime $\left(<300 \mathrm{~mm} \mathrm{yr}^{-1}\right)$ without vegetation. At the boundary between Nigeria and Cameroon near the Gulf of Guinea $\left(10^{\circ} \mathrm{E}, 5^{\circ} \mathrm{N}\right)$, in contrast, a high $\bar{P}(>3000 \mathrm{~mm})$ makes the prediction of forest vegetation very robust (see also top left panel of Fig. 5). Low $\bar{R}$ is found in three regions (Fig. 7b). The first region is the long band of savanna between 5 and $12^{\circ} \mathrm{N}$. Intermediate $\bar{R}$ is strongly related to stable savanna vegetation (top right panel of Fig. 5). The other two regions are the west and the east of the Congo basin $\left(\left(10^{\circ} \mathrm{E}, 3^{\circ} \mathrm{S}-\right.\right.$ $\left.5^{\circ} \mathrm{N}\right)$ and $\left.\left(25-30^{\circ} \mathrm{E}, 3^{\circ} \mathrm{S}-3^{\circ} \mathrm{N}\right)\right)$. In these regions $\bar{R}$ is low $\left(<180 \mathrm{~W} \mathrm{~m}^{-2}\right)$. However, $\bar{R}$ cannot determine the vegetation type in the majority of the Congo basin area $(0.65<$ $w_{k}<1.0$ ), which is forest dominated. The uncertainty estimations for $E_{\mathrm{p}}$ and $L_{\mathrm{D}}$ are similar (Fig. $7 \mathrm{c}$ and e). The predicted band of savanna is narrower than produced with $\bar{R}$. However, the Congo basin is mainly highlighted with low uncertainty $\left(0.39<w_{k}<0.54\right)$. The stable forest vegetation predicted by $\Delta_{\mathrm{p}}$ occupies a larger area than produced with $E_{\mathrm{p}}$ and $L_{\mathrm{D}}$ with lower uncertainty $\left(w_{k}<0.4\right)$, which demonstrates $\Delta_{\mathrm{p}}$ to be a better climatic indicator for stable forest. Savanna can be well predicted by $\rho_{\bar{P}_{\mathrm{m}}}, \bar{R}_{\mathrm{m}}$ with relatively low uncertainty, but the result is not as good as produced with $\bar{R}$, $E_{\mathrm{p}}$ or $L_{\mathrm{D}}$. However, $\rho_{\bar{P}_{\mathrm{m}}, \bar{R}_{\mathrm{m}}}$ can predict the land cover in the west of the Congo basin, where a weak positive correlation between rainfall and radiation is displayed.
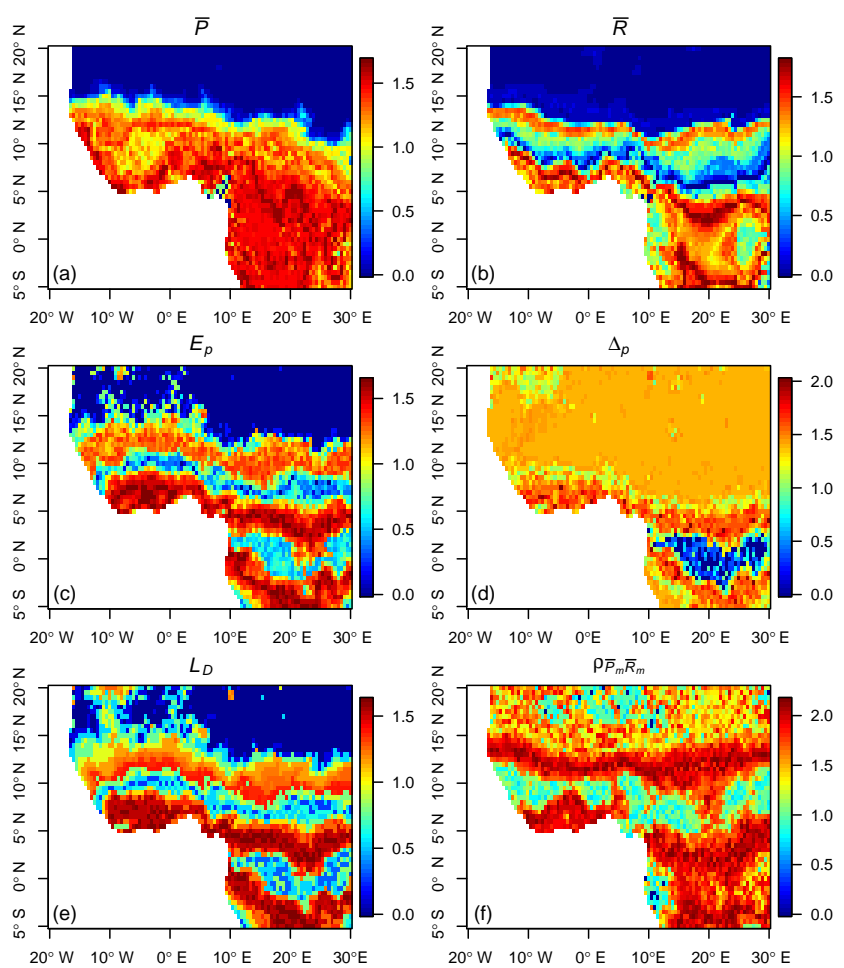

Figure 7. Uncertainty index of the six climatic variables for land cover prediction. A low value ( $w_{k}$ is defined in Eq. 5 ) denotes a high confidence of the specific variable to predict the local land cover types.

\subsection{Prediction and potential shifts of land cover}

Figure $8 \mathrm{a}-\mathrm{c}$ displays the predicted land cover using three combinations of climatic indicators. In Fig. 8a LC is predicted using solely precipitation as climatic indicator. Stable forest is only found for several grid cells around $\left(10^{\circ} \mathrm{E}, 5^{\circ} \mathrm{N}\right)$ with high rainfall ( $>3000 \mathrm{~mm} \mathrm{yr}^{-1}$ ). The area where both savanna and forest can exist ranges from the coast of Guinea to the Congo basin. The Congo basin is currently covered by forest, but is predicted to be unstable and has the potential to shift to the savanna state using $\bar{P}$ only. The region around $\left(14^{\circ} \mathrm{W}, 10^{\circ} \mathrm{N}\right)$ is also predicted to be forest dominated, while in reality it is covered by a G-S vegetation type (Fig. 4a). With high $L_{\mathrm{D}}(>0.7)$ and radiation $\left(>230 \mathrm{~W} \mathrm{~m}^{-2}\right)$, S-F hardly occurs.

Figure 8b shows LC prediction generated using both $\bar{P}$ and $L_{\mathrm{D}}$ as climatic indicators. Stable forest vegetation is predicted in a small area of the Congo basin. The forestdominated area occurs on the south coast of Liberia and Ghana $\left(\left(10^{\circ} \mathrm{W}, 5^{\circ} \mathrm{N}\right)\right.$ to $\left.\left(1^{\circ} \mathrm{W}, 5^{\circ} \mathrm{N}\right)\right)$, which coincides with observations. In addition, stable savanna is present as a shallow band around $10^{\circ} \mathrm{N} . \Delta_{\mathrm{p}}$ is added as climatic indicator in Fig. 8c, which leads to an increase of the area with stable forest cover. The stable savanna region shown in Fig. $8 \mathrm{~b}$ is reduced in areal extent. 


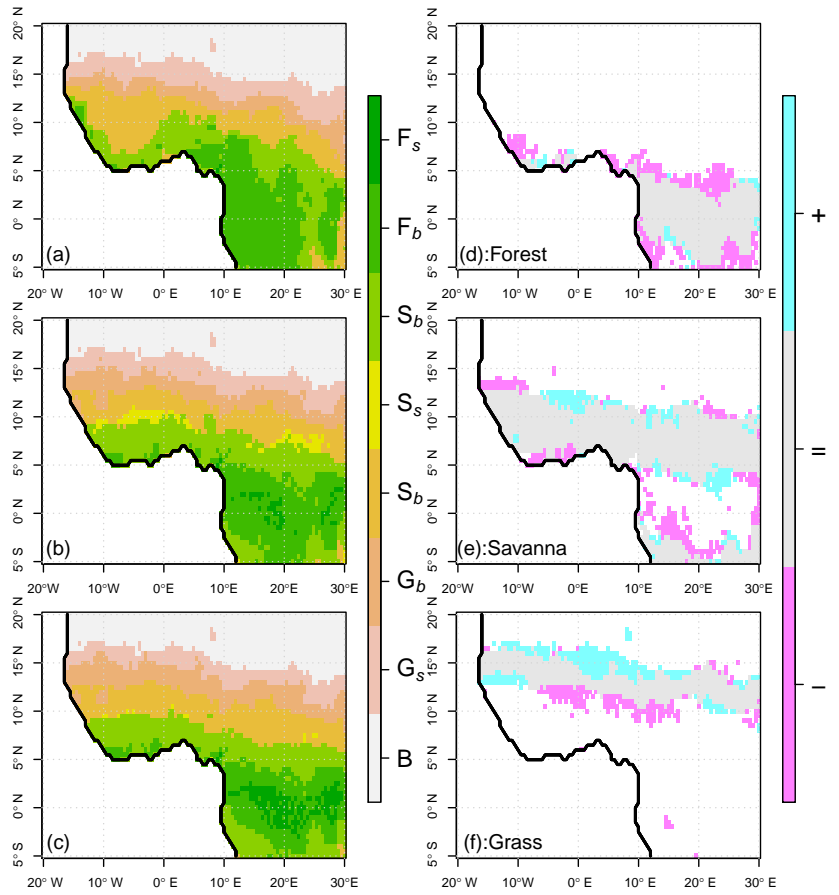

Figure 8. (a, b, c) Predicted land cover type using different combinations of climatic indicators. (a) Only total rainfall $\bar{P}$, (b) $\bar{P}$ and length of the dry season $L_{\mathrm{D}}$, (c) $\bar{P}, L_{\mathrm{D}}$ and the entropy of the relative monthly precipitation $\Delta_{\mathrm{p}}$. B is bare soil, $\mathrm{G}_{\mathrm{s}}$ is stable grass; $\mathrm{G}_{\mathrm{b}}$ is bimodality dominated by grass, $\mathrm{S}_{\mathrm{b}}$ is bimodality dominated by savanna, $S_{\mathrm{S}}$ is stable savanna, $\mathrm{F}_{\mathrm{b}}$ is bimodality dominated by forest and $F_{s}$ is stable forest. Note that $S_{b}$ appears twice. The top $S_{b}$ is a bimodality between savanna and forest, and the bottom one represents a bimodality between grass and savanna. (d, e, f) Difference between predicted and observed land cover based on Figs. 8c and 4a respectively. In (d), the area marked by " + " is predicted to be dominated by forest but currently is covered by other states. The area marked by "-" is predicted to be covered by other states but currently is dominated by forest. The area marked by "=" is predicted to be dominated by forest and currently is dominated by forest. For (e) and (f) the same signs are used for savanna and grass.

Figure $8 \mathrm{~d}-\mathrm{f}$ illustrates the difference between observed and predicted LC (Fig. 8c). For each pattern, the mean value of $\bar{P}, \Delta_{\mathrm{p}}$ and $L_{\mathrm{D}}$ are listed in Table 3. Note that Fig. 8d-f only shows the potential shift of the specific state, whereas the values in Table 3 show the explicit direction of the potential shift. For instance, the "+" in Fig. 8e indicates the regions that have potential to shift from other land cover types to the savanna state. This includes two possibilities: $\mathrm{F} \rightarrow \mathrm{S}$ and $\mathrm{G} \rightarrow \mathrm{S}$ (in Table 3), representing patterns where current forest and current grass can shift to savanna.

Figure $8 \mathrm{~d}$ shows that a large area covered by forest has the potential for a transition to savanna. It includes the forest area in Guinea and a large boundary of the Congo basin. However, forest recovery can only occur in a few areas at the border between $\mathrm{F}$ and $\mathrm{S}$ states, including the south coast of Ghana and Côte d'Ivoire. The $\bar{P}\left(1513 \mathrm{~mm} \mathrm{yr}^{-1}\right.$, Table 3$)$ of the $\mathrm{S} \rightarrow \mathrm{F}$
Table 3. The mean value of $\bar{P}, \Delta_{\mathrm{p}}$ and $L_{\mathrm{D}}$ of different patterns shown in Fig. 8d-f. The first column represents the status of the specific patterns. For instance, $\mathrm{F} \rightarrow \mathrm{S}$ indicates the patterns that are observed as forest but predicted to be savanna.

\begin{tabular}{lrrr}
\hline $\begin{array}{l}\text { Land cover } \\
\text { change }\end{array}$ & $\begin{array}{r}\bar{P} \\
\left(\mathrm{~mm} \mathrm{yr}^{-1}\right)\end{array}$ & $\begin{array}{r}\Delta_{\mathrm{p}} \\
(-)\end{array}$ & $\begin{array}{r}L_{\mathrm{D}} \\
(1)\end{array}$ \\
\hline $\mathrm{F} \rightarrow \mathrm{F}$ & 1601 & 0.70 & 0.30 \\
$\mathrm{~F} \rightarrow \mathrm{S}$ & 1481 & 0.92 & 0.40 \\
$\mathrm{~S} \rightarrow \mathrm{F}$ & 1513 & 0.78 & 0.32 \\
$\mathrm{~S} \rightarrow \mathrm{S}$ & 1174 & 0.96 & 0.49 \\
$\mathrm{~S} \rightarrow \mathrm{G}$ & 695 & 1.00 & 0.66 \\
$\mathrm{G} \rightarrow \mathrm{S}$ & 887 & 1.00 & 0.59 \\
$\mathrm{G} \rightarrow \mathrm{G}$ & 525 & 1.00 & 0.68 \\
$\mathrm{G} \rightarrow \mathrm{B}$ & 259 & 1.00 & 0.75 \\
$\mathrm{~B} \rightarrow \mathrm{G}$ & 378 & 1.00 & 0.70 \\
\hline
\end{tabular}

patterns is slightly higher than the $\bar{P}\left(1481 \mathrm{~mm} \mathrm{yr}^{-1}\right)$ of the $\mathrm{F} \rightarrow \mathrm{S}$ patterns, but the $\Delta_{\mathrm{p}}(0.78$ for $\mathrm{S} \rightarrow \mathrm{F} ; 0.92$ for $\mathrm{F} \rightarrow \mathrm{S})$ and $L_{\mathrm{D}}(0.32$ for $\mathrm{S} \rightarrow \mathrm{F} ; 0.40$ for $\mathrm{F} \rightarrow \mathrm{S})$ show a considerable difference. It implies that in such regions the seasonality of precipitation is more important to forest than the mean annual precipitation. The regions with low $\Delta_{\mathrm{p}}$ and $L_{\mathrm{D}}$ are more likely to be covered by forest. The potential transition of savanna into another vegetation type is shown in two regions (Fig. 8e). For the $\mathrm{S} \rightarrow \mathrm{G}$ transition, there is an increasing trend of savanna between $8^{\circ} \mathrm{W}$ and $19^{\circ} \mathrm{E}$, suggesting regreening of the Sahel. This is compensated by a replacement of savanna by grass in the adjacent areas. Compared with the transitions between forest and savanna, the differences between $\mathrm{S} \rightarrow \mathrm{G}$ and $\mathrm{G} \rightarrow \mathrm{S}$ mainly exist in $\bar{P}$ (695 and $\left.887 \mathrm{~mm} \mathrm{yr}^{-1}\right)$ and $L_{\mathrm{D}}(0.66$ and 0.59$)$ rather than in $\Delta_{\mathrm{p}}$ (Table 3). A large area of the Sahara has the potential to be recovered by grassland due to sufficient $\bar{P}\left(378 \mathrm{~mm} \mathrm{yr}^{-1}\right)$ to sustain grassland (Fig. 8f and Table 3). The main recovery occurs in the northern Sahel front between $15^{\circ} \mathrm{W}$ and $20^{\circ} \mathrm{E}$. Especially in the centre of this front (between $0^{\circ} \mathrm{E}$ and $10^{\circ} \mathrm{E}$ ), the regreening trend can promote vegetation extension approximately $3^{\circ}$ northward.

\section{Discussion}

\subsection{Conditional analysis of bimodalities}

Multiple studies (e.g. Staver et al., 2011b; Hirota et al., 2011; Yin et al., 2014a; Baudena et al., 2015) found that the observed distribution of woody cover $(W)$ provides evidence that alternative vegetation states may exist under a given precipitation regime. Due to the interactions between vegetation and local climate (Rietkerk et al., 2002; Staver et al., 2011a; Seneviratne et al., 2010), alternative stable states can exist. Therefore we have hypothesized that bimodality should be found in both vegetation and climate variables, especially for 
western Africa, where land surface is strongly coupled with atmosphere (Koster et al., 2004).

Our results confirm our hypotheses and show that alternative states also exist in above-ground biomass $(B)$ and mean shortwave radiation $(\bar{R})$. Two modes of $W$ generate different amounts of evapotranspiration under the same $\bar{P}$. It strongly influences radiation regimes through cloud formation (Bonan, 2008; Seneviratne et al., 2010). Furthermore, rainfall seasonality, which can be represented by $\bar{R}$, affects the temporal distribution of water (van den Hurk and van Meijgaard, 2009; Good and Caylor, 2011) and the fire frequency (Higgins et al., 2000; Archibald et al., 2009; Mayer and Khalyani, 2011), which in turn influences the $W$. Although the interactions between $W$ and $\bar{R}$ are extremely complex, the bimodality found in both variables reveals the existence of vegetation-climate interactions.

By applying conditional histograms in the analysis of distributions of $B$ and $\bar{R}$ we found that our hypothesis was not totally true. For instance, vegetation under high $\bar{R}$ must have low $W$, but low $W$ does not mean that it correlates with high $\bar{R}$. Low $W$ indicates that the vegetation has low $B$, but high $W$ occurs in both low and high $B$ cases. These results are summarized in Table 2, containing four cases. The first case is that with low $B$ and high $\bar{R}$ only low $W$ is found. It is a typical condition for savanna states. Low $B$ implies weak colonization ability of woody plants while high $\bar{R}$ represents high rainfall seasonality. Both of them provide ideal conditions for grass growth in the wet season and fire occurrence during the dry season, suggesting that the savanna state here is very stable. This is consistent with findings of Staver et al. (2011b) for areas where annual rainfall exceeds $1000 \mathrm{~mm} \mathrm{yr}^{-1}$ : in areas with a long dry season (associated with high radiation), only savannas with low woody cover were observed.

The second case is that only high $W$ can exist under the condition of high $B$ and low $\bar{R}$. It suggests that high biomass and low variation of rainfall seasonality are sufficient conditions for a stable forest state. The importance of rainfall seasonality on vegetation cover was highlighted before in various studies Baudena and Provenzale (2008). Furthermore, Good and Caylor (2011) did find for Africa that areas with similar annual rainfall amounts have higher woody cover if the rainfall climatology is dominated by frequent lowintensity precipitation events.

For the previous two cases, the mode of $W$ can be determined because the vegetation-climate interactions under the given conditions are very strong. For instance, low $\bar{R}$ provides a steady rainfall climatology for high $B$ and in turn high $B$ reinforces the stability of low $\bar{R}$. With a disturbance, for instance rainfall decreasing during the dry season, the high $B$ can remain as high cloud cover through evapotranspiration to avoid further water loss, which in turn keeps $\bar{R}$ at a low level. However, apart from these two stable states we also find two unstable states. The first is high $B$ and high $\bar{R}$, which is rarely observed in our study. It suggests that the system would fast shift to the two stable states once this situation occurs.
The most interesting condition is low $B$ and low $\bar{R}$, where the bimodality of $W$ is still found. This status can be observed at the boundary between savanna and forest. In this region, $B$ is low due to the fire effect from the savanna side but woody plants can benefit from high cloud cover from the forest side. Thus they can produce both low and high $W$, which is subject to the strength of fire and cloud cover. In this case the system can easily shift from one state to another. If high $W$ occurs, it can reinforce the transpiration-cloud feedback and get rid of fire. Consequently, this region will be colonized by forest. Otherwise, fire frequency increases due to low $W$ and the savanna will extend to the forest.

Based on the bifurcation theory, ecosystems may form alternative stable states under the same climate condition due to different feedback mechanisms. In this study, the mean annual precipitation is the general climate condition. Thus the observed bimodalities of $B$ and $\bar{R}$ are strong evidence for alternative stable states under different $\bar{P}$ bands. Moreover we notice that $\bar{R}$ can be an ideal measure of the strength of the vegetation-climate interactions, through which we can estimate the stability of the two $W$ modes. Our results (in Table 2) demonstrate that unimodality of $W$ is found under specific conditions of $W$ and $\bar{R}$. It implies that the $W$ state is stable under such conditions. However bimodality of $W$ still exists under an intermediate status: low $B$ and low $\bar{R}$, revealing where critical transitions might occur. Numerous studies tried to find early warning signals of possible critical transitions through different approaches (Scheffer et al., 2009; Kéfi et al., 2007; Dakos et al., 2011; Tirabassi et al., 2014; Yin et al., 2016). However they only focused on indicators from the dynamics of vegetation to estimate ecosystem states. The essential cause of most alternative stable states in ecology, feedback mechanisms (Cochrane et al., 1999; Rietkerk et al., 2002; Dekker et al., 2010), is not explicitly considered. This study uses a climatic variable $\bar{R}$ and a proxy variable of woody plants' age $B$ to estimate the stability of vegetation states through measuring the strength of the specific feedback mechanism. This approach does not need long time series data of vegetation dynamics, only a screen shot of vegetation biomass and short time observations of a proper climatic variable. However we agree that this approach does not allow the quantification of complex feedbacks between, e.g. land cover and local climate, for which more complex observations and analyses are needed.

This study simply tests the climatic approach in western Africa. In the next step, this approach will be extended to the whole tropical region to estimate the stability of vegetation states at global scale. Recently a new version of MODIS VCF (Collection 5) has become available (DiMiceli et al., 2010). Xu et al. (2015) found that the multimodality of boreal plants still exists in the new version, but the density distribution varies significantly compared with the previous version Hansen et al. (Collection 3, 2003). Thus the difference between the two VCF versions in the tropical area should be carefully investigated before analysis. Moreover, it will be of 
interest to investigate whether the two modes of $W$ from Collection 3 are equal to that from Collection 5 according to the conditional histogram.

\subsection{Climate indicators and land cover prediction}

Although rainfall is the primary driver of the maximum woody cover in Africa (Sankaran et al., 2005; Bucini and Hanan, 2007), the land cover predicted by the mean annual precipitation is highly uncertain due to complex ecohydrological processes and sensitivities. It is essential to consider rainfall seasonality (Good and Caylor, 2011; Staver et al., 2011b), and clearly helps in understanding vegetation pattern anomalies, for instance during drought conditions (Good and Caylor, 2011). However, other climatic indicators play important roles as well.

In this study, we link vegetation patterns to six climatic indicators, including mean annual precipitation, rainfall seasonality, incoming shortwave radiation and correlation coefficient of $\bar{P}_{\mathrm{m}}$ and $\bar{R}_{\mathrm{m}}$. Taking total rainfall as the only indicator results in high uncertainty of the LC prediction (Fig. 7a). Overlapping vegetation states for a given precipitation climate (Fig. 5) can be misinterpreted as the existence of a bimodal vegetation structure. Mean annual shortwave radiation explains more variability in observed LC patterns (Fig. 7b). It is closely related to savanna and increases confidence in estimated vegetation states in the west of the Congo basin. This is also found from $\rho_{\bar{P}_{\mathrm{m}}, \bar{R}_{\mathrm{m}}}$, indicating a relatively strong positive correlation between $\bar{P}_{\mathrm{m}}$ and $\bar{R}_{\mathrm{m}}$. The precipitation seasonality relates to the strong monsoon season modulates cloud cover, which leads to a low or negative value of $\rho_{\bar{P}_{\mathrm{m}},}, \bar{R}_{\mathrm{m}}$. The western Congo basin, however, has a continuous high cloud coverage. The variation of the radiation is thus strongly linked to the solar zenith angle and the correlation between rainfall and radiation is weakly positive instead of negative as is found in most regions.

Predictions of LC with three incremental combinations of climatic indicators are illustrated and compared to observed LC distributions (Fig. 8). Using $\bar{P}$ alone (Fig. 8a) yields similar LC patterns to the findings of (Staver et al., 2011b). In the Congo basin with intermediate rainfall amounts $(1300<$ $\bar{P}<2500 \mathrm{~mm} \mathrm{yr}^{-1}$ ) a potential bimodal $\mathrm{S}-\mathrm{F}$ vegetation structure (currently covered by forest) is found (Fig. 8a). However, the rainfall seasonality in this area is relatively low compared to other climatic zones. The precipitation amount during the dry season is high enough to prevent fire occurrence, leading to a relatively stable ecosystem with low probability of bimodal vegetation states.

A new analysis in this comparison is the climate driven potential LC transition in western Africa. The results (Fig. 8) show that a strong reduction in tropical forest area is possible due to high seasonality (Table 3 ). Predicted grassland expansion around $15^{\circ} \mathrm{N}$ coincides well with observations (Dardel et al., 2014). However, the regreening trend of savanna around $10^{\circ} \mathrm{N}$ was not detected by observations as the remote sensing data used are fairly insensitive to possible changes in woody cover during the growing season (Dardel et al., 2014).

Our analysis is limited by the use of a short ( 6 years) climate data set (Boone et al., 2009). Prediction of future LC transition related to climate change is hard (Higgins and Scheiter, 2012), but could be complemented by including climate model data (Seneviratne et al., 2013). Changes in $\mathrm{CO}_{2}$ concentration (Higgins and Scheiter, 2012) and factors like soil type (Dardel et al., 2014), plant diversity (Claussen et al., 2013; Dekker, 2013) and topography (Klausmeier, 1999) have not been included in our analysis. Including dynamic vegetation-climatic interactions (Dekker et al., 2007; Rietkerk et al., 2011; Siteur et al., 2014), vegetation competition for limited resources (Loon et al., 2014; Scheffer et al., 2014) and grazing pressure in these systems (Kéfi et al., 2007) further promotes the understanding of the complexity of the potential woody cover prediction (Dijkstra, 2011).

Apart from natural factors, human activities (e.g. deforestation, grazing and urbanization) also significantly influence the tropical ecosystem. In fact, based on the GlobCover data we found that over $80 \%$ of an area can be affected by humans in specific climatic grid cells $\left(0.5^{\circ}\right.$ resolution). Estimating the amount and type of land use change is difficult as it involves many different social processes, such as economy, cultivation culture and policy both on local and global scales. In turn these land use changes interact with climate change as well. Thus its contributions to climate change and ecosystems should be carefully investigated to improve the prediction of potential land cover change.

\section{Conclusions}

Observed bimodality of woody cover suggests that alternative stable states may exist under the same precipitation band due to vegetation-climate interactions. In this study we find that bimodality also exists in the density distribution of mean annual incoming shortwave radiation and aboveground biomass. The bimodality of climatic variables provide another evidence of strong vegetation-climate interaction in tropical regions. By means of analysing conditional histograms, we find two stable conditions under which the mode of woody cover can be determined. It indicates that a climatic variable, which should be a measure of the strength of vegetation-climate interactions, can be used to estimate the stability of vegetation states. We also find that the bimodality of woody cover still exists under the condition of low mean annual radiation and low above-ground biomass. It is demonstrated as the environment where vegetation state is unstable and critical transition can occur.

Although mean annual precipitation is an important driver of maximum woody cover variations, it is not a sufficient climatic indicator to predict potential land cover types. Including mean shortwave radiation and rainfall seasonality in- 
creases the confidence of land cover prediction. The normalized difference of monthly-averaged precipitation is a good predictor for stable forest states, which is important to understand vegetation stability in high tropical rainfall areas in the Congo basin. By comparing the observed and predicted land cover types, we find that the area of the tropical forest is under pressure, while the savanna and grassland trend in the Sahel suggests a regreening of western Africa under current climate conditions.

\section{The Supplement related to this article is available online at doi:10.5194/bg-13-3343-2016-supplement.}

Author contributions. Zun Yin, Stefan C. Dekker and Bart J. J. M. van den Hurk designed the research, Zun Yin performed the research and all authors contributed to the interpretation of the results and the writing of the manuscript.

Acknowledgements. We would like to thank Aaron Boone for providing the climatic data from the ALMIP project. We gratefully acknowledge five anonymous referees for their useful comments. We also thank Utrecht University for financial support of this research through a Focus and Mass project within the sustainability theme.

Edited by: F. Wittmann

\section{References}

Archibald, S., Roy, D. P., Wilgen, V., Brian, W., and Scholes, R. J.: What limits fire? An examination of drivers of burnt area in Southern Africa, Glob. Change Biol., 15, 613-630, 2009.

Baccini, A., Laporte, N., Goetz, S. J., Sun, M., and Dong, H.: A first map of tropical Africa's above-ground biomass derived from satellite imagery, Environ. Res. Lett., 3, 045011, doi:10.1088/1748-9326/3/4/045011, 2008.

Baudena, M. and Provenzale, A.: Rainfall intermittency and vegetation feedbacks in drylands, Hydrol. Earth Syst. Sci., 12, 679-689, doi:10.5194/hess-12-679-2008, 2008.

Baudena, M., D'Andrea, F., and Provenzale, A.: An idealized model for tree-grass coexistence in savannas: the role of life stage structure and fire disturbances, J. Ecol., 98, 74-80, 2010.

Baudena, M., Dekker, S. C., van Bodegom, P. M., Cuesta, B., Higgins, S. I., Lehsten, V., Reick, C. H., Rietkerk, M., Scheiter, S., Yin, Z., Zavala, M. A., and Brovkin, V.: Forests, savannas, and grasslands: bridging the knowledge gap between ecology and Dynamic Global Vegetation Models, Biogeosciences, 12, 18331848, doi:10.5194/bg-12-1833-2015, 2015.

Biernacki, C., Celeux, G., and Govaert, G.: Assessing a mixture model for clustering with the integrated completed likelihood, IEEE T. Pattern Anal., 22, 719-725, 2000.
Bonan, G.: Forests and climate change: forcings, feedbacks, and the climate benefits of forests, Science, 320, 1444-1449, 2008.

Bontemps, S., Defourny, P., Van Bogaert, E., Arino, O., Kalogirou, V., and Perez, J. R.: GLOBCOVER 2009 Products Description and Validation Report, tech. rep., UCLouvain \& ESA Team, MEDIAS, Toulouse, France, 2011.

Boone, A., Rosnay, P., Balsamo, G., Beljaars, A., Chopin, F., Decharme, B., Delire, C., Ducharne, A., Gascoin, S., Grippa, M. Guichard, F., Gusev, Y., Harris, P., Jarlan, L., Kergoat, L., Mougin, E., Nasonova, O., Norgaard, A., Orgeval, T., Ottlé, C., Poccard-Leclercq, I., Polcher, J., Sandholt, I., Saux-Picart, S., Taylor, C., and Xue, Y.: The AMMA Land Surface Model Intercomparison Project (ALMIP), B. Am. Meteorol. Soc., 90, 18651880, 2009.

Bucini, G. and Hanan, N. P.: A continental-scale analysis of tree cover in African savannas, Global Ecol. Biogeogr., 16, 593-605, 2007.

Claussen, M., Bathiany, S., Brovkin, V., and Kleinen, T.: Simulated climate-vegetation interaction in semi-arid regions affected by plant diversity, Nat. Geosci., 6, 954-958, 2013.

Cochrane, M. A., Alencar, A., Schulze, M. D., Souza, C. M., Nepstad, D. C., Lefebvre, P., and Davidson, E. A.: Positive feedbacks in the fire dynamic of closed canopy tropical forests, Science, 284, 1832-1835, 1999.

Dakos, V., Kéfi, S., Rietkerk, M., Nes, Egbert, H. v., and Scheffer, M.: Slowing Down in Spatially Patterned Ecosystems at the Brink of Collapse, Am. Nat., 177, E153-E166, 2011.

Dardel, C., Kergoat, L., Hiernaux, P., Mougin, E., Grippa, M., and Tucker, C. J.: Re-greening Sahel: 30 years of remote sensing data and field observations (Mali, Niger), Remote Sens. Environ., 140, 350-364, 2014.

Dekker, S. C.: Palaeoclimate: biodiversity-dominated feedback, Nat. Geosci., 6, 903-904, 2013.

Dekker, S., Rietkerk, M., and Bierkens, M.: Coupling microscale vegetation-soil water and macroscale vegetation-precipitation feedbacks in semiarid ecosystems, Glob. Change Biol., 13, 671678, 2007.

Dekker, S. C., de Boer, H. J., Brovkin, V., Fraedrich, K., Wassen, M. J., and Rietkerk, M.: Biogeophysical feedbacks trigger shifts in the modelled vegetation-atmosphere system at multiple scales, Biogeosciences, 7, 1237-1245, doi:10.5194/bg-7-12372010, 2010.

Dijkstra, H.: Vegetation pattern formation in a semi-arid climate, Int. J. Bifurcat. Chaos, 21, 3497-3509, 2011.

DiMiceli, C. M., Carroll, M. L., Sohlberg, R. A., Huang, C., Hansen, M. C., and Townshend, J. R. G.: Annual global automated MODIS Vegetation Continuous Fields (MOD44B) at $250 \mathrm{~m}$ spatial resolution for data years beginning day 65, 2000 2010, Tech. Rep., University of Maryland, College Park, Maryland, 2010.

Entekhabi, D., Rodriguez-Iturbe, I., and Bras, R.: Variability in large-scale water balance with land surface-atmosphere interaction, J. Climate, 5, 798-813, 1992.

Feng, X., Porporato, A., and Rodriguez-Iturbe, I.: Changes in rainfall seasonality in the tropics, Nature Climate Change, 3, 811815, 2013.

Good, S. P. and Caylor, K. K.: Climatological determinants of woody cover in Africa, P. Natl. Acad. Sci. USA, 108, 4902-4907, 2011. 
Grün, B. and Leisch, F.: Fitting finite mixtures of generalized linear regressions in R, Comput. Stat. Data An., 51, 5247-5252, 2007.

Hanan, N. P., Tredennick, A. T., Prihodko, L., Bucini, G., and Dohn, J.: Analysis of stable states in global savannas: is the CART pulling the horse?, Global Ecol. Biogeogr., 23, 259-263, 2014.

Hanan, N. P., Tredennick, A. T., Prihodko, L., Bucini, G., and Dohn, J.: Analysis of stable states in global savannas - a response to Staver and Hansen, Global Ecol. Biogeogr., 24, 988989, 2015.

Hansen, M. C., DeFries, R. S., Townshend, J. R. G., Carroll, M., Dimiceli, C., and Sohlberg, R. A.: Global percent tree cover at a spatial resolution of 500 meters: first results of the MODIS vegetation continuous fields algorithm, Earth Interact., 7, 1-15, 2003.

Higgins, S. I. and Scheiter, S.: Atmospheric $\mathrm{CO}_{2}$ forces abrupt vegetation shifts locally, but not globally, Nature, 488, 209-212, 2012.

Higgins, S. I., Bond, W. J., and Trollope, W. S.: Fire, resprouting and variability: a recipe for grass-tree coexistence in savanna, J. Ecol., 88, 213-229, 2000.

Hirota, M., Holmgren, M., Van Nes, E. H., and Scheffer, M.: Global resilience of tropical forest and savanna to critical transitions, Science, 334, 232-235, 2011.

Kéfi, S., Rietkerk, M., Alados, C., Pueyo, Y., Papanastasis, V., ElAich, A., and De Ruiter, P.: Spatial vegetation patterns and imminent desertification in Mediterranean arid ecosystems, Nature, 449, 213-217, 2007.

Kéfi, S., Holmgren, M., and Scheffer, M.: When can positive interactions cause alternative stable states in ecosystems?, Funct. Ecol., 30, 88-97, 2016.

Klausmeier, C.: Regular and irregular patterns in semiarid vegetation, Science, 284, 1826-1828, 1999.

Koster, R. D., Dirmeyer, P. A., Guo, Z., Bonan, G., Chan, E., Cox, P., Gordon, C. T., Kanae, S., Kowalczyk, E., Lawrence, D., Liu, P., Lu, C.-H., Malyshev, S., McAvaney, B., Mitchell, K., Mocko, D., Oki, T., Oleson, K., Pitman, A., Sud, Y. C., Taylor, C. M., Verseghy, D., Vasic, R., Xue, Y., and Yamada, T.: Regions of strong coupling between soil moisture and precipitation, Science, 305, 1138-1140, 2004.

Loon, M. P., Schieving, F., Rietkerk, M., Dekker, S. C., Sterck, F., and Anten, N. P.: How light competition between plants affects their response to climate change, New Phytol., 203, 1253-1265, doi:10.1111/nph.12865, 2014.

Mayer, A. L. and Khalyani, A. H.: Grass trumps trees with fire, Science, 334, 188-189, 2011.

Rietkerk, M., Boerlijst, M., van Langevelde, F., HilleRisLambers, R., van de Koppel, J., Kumar, L., Prins, H., and de Roos, A.: Self-organization of vegetation in arid ecosystems, Am. Nat., 160, 524-530, 2002.

Rietkerk, M., Dekker, S. C., de Ruiter, P. C., and van de Koppel, J.: Self-organized patchiness and catastrophic shifts in ecosystems, Science, 305, 1926-1929, 2004.

Rietkerk, M., Brovkin, V., van Bodegom, P. M., Claussen, M., Dekker, S. C., Dijkstra, H. A., Goryachkin, S. V., Kabat, P., van Nes, E. H., Neutel, A.-M., Nicholson, S. E., Nobre, C., Petoukhov, V., Provenzale, A., Scheffer, M., and Seneviratne, S. I.: Local ecosystem feedbacks and critical transitions in the climate, Ecol. Complex., 8, 223-228, 2011.
Roy, D. P., Boschetti, L., Justice, C. O., and Ju, J.: The collection 5 MODIS burned area product-Global evaluation by comparison with the MODIS active fire product, Remote Sens. Environ., 112, 3690-3707, 2008.

Sankaran, M., Hanan, N. P., Scholes, R. J., Ratnam, J., Augustine, D. J., Cade, B. S., Gignoux, J., Higgins, S. I., Le Roux, X., Ludwig, F., Ardo, J., Banyikwa, F., Bronn, A., Bucini, G., Caylor, K. K., Coughenour, M. B., Diouf, A., Ekaya, W., Feral, C. J., February, E. C., Frost, P. G. H., Hiernaux, P., Hrabar, H., Metzger, K. L., Prins, H. H. T., Ringrose, S., Sea, W., Tews, J., Worden, J., and Zambatis, N.: Determinants of woody cover in African savannas, Nature, 438, 846-849, 2005.

Scheffer, M., Carpenter, S., Foley, J. A., Folke, C., and Walker, B.: Catastrophic shifts in ecosystems, Nature, 413, 591-596, 2001.

Scheffer, M., Bascompte, J., Brock, W. A., Brovkin, V., Carpenter, S. R., Dakos, V., Held, H., Van Nes, E. H., Rietkerk, M., and Sugihara, G.: Early-warning signals for critical transitions, Nature, 461, 53-59, 2009.

Scheffer, M., Vergnon, R., Cornelissen, J. H. C., Hantson, S., Holmgren, M., Nes, Egbert, H. v., and Xu, C.: Why trees and shrubs but rarely trubs?, Trends Ecol. Evol., 29, 433-434, 2014.

Seneviratne, S., Corti, T., Davin, E., Hirschi, M., Jaeger, E., Lehner, I., Orlowsky, B., and Teuling, A.: Investigating soil moisture-climate interactions in a changing climate: a review, Earth-Sci. Rev., 99, 125-161, 2010.

Seneviratne, S. I., Wilhelm, M., Stanelle, T., Hurk, B., Hagemann, S., Berg, A., Cheruy, F., Higgins, M. E., Meier, A., Brovkin, V., Claussen, M., Ducharne, A., Dufresne, J. L., Findell, K. L., Ghattas, J., Lawrence, D. M., Malyshev, S., Rummukainen, M., and Smith B.: Impact of soil moisture-climate feedbacks on CMIP5 projections: first results from the GLACECMIP5 experiment, Geophys. Res. Lett., 40, 5212-5217, 2013.

Siteur, K., Eppinga, M. B., Karssenberg, D., Baudena, M., Bierkens, M. F., and Rietkerk, M.: How will increases in rainfall intensity affect semiarid ecosystems?, Water Resour. Res., 50, 5980-6001, doi:10.1002/2013WR014955, 2014.

Staver, A. C. and Hansen, M. C.: Comment on "Analysis of stable states in global savannas: is the CART pulling the horse?", Global Ecol. Biogeogr., 24, 985-987, 2015.

Staver, A. C., Archibald, S., and Levin, S.: Tree cover in subSaharan Africa: rainfall and fire constrain forest and savanna as alternative stable states, Ecology, 92, 1063-1072, 2011a.

Staver, A. C., Archibald, S., and Levin, S. A.: The global extent and determinants of savanna and forest as alternative biome states, Science, 334, 230-232, 2011b.

Tirabassi, G., Viebahn, J., Dakos, V., Dijkstra, H., Masoller, C., Rietkerk, M., and Dekker, S.: Interaction network based earlywarning indicators of vegetation transitions, Ecol. Complex., 19, 148-157, 2014.

van den Hurk, B. J. J. M. and van Meijgaard, E.: Diagnosing landatmosphere interaction from a regional climate model simulation over West Africa, J. Hydrometeorol., 11, 467-481, 2009.

Van Nes, E. H., Holmgren, M., Hirota, M., and Scheffer, M.: Response to comment on "Global resilience of tropical forest and Savanna to critical transitions", Science, 336, 541-541, 2012.

Xu, C., Holmgren, M., Van Nes, E. H., Hirota, M., Chapin III, F. S., and Scheffer, M.: A Changing Number of Alternative States in the Boreal Biome: Reproducibility Risks 
of Replacing Remote Sensing Products, PloS One, 10, doi:10.1371/journal.pone.0143014, 2015.

Yin, Z., Dekker, S. C., van den Hurk, B. J. J. M., and Dijkstra, H. A.: Effects of vegetation structure on biomass accumulation in a Balanced Optimality Structure Vegetation Model (BOSVM v1.0), Geosci. Model Dev., 7, 821-845, doi:10.5194/gmd-7-821-2014, 2014a.

Yin, Z., Dekker, S. C., van den Hurk, B. J. J. M., and Dijkstra, H. A.: Bimodality of woody cover and biomass across the precipitation gradient in West Africa, Earth Syst. Dynam., 5, 257-270, doi:10.5194/esd-5-257-2014, 2014b.
Yin, Z., Dekker, S. C., Rietkerk, M., van den Hurk, B. J. J. M., and Dijkstra, H. A.: Network based early warning indicators of vegetation changes in a land-atmosphere model, Ecol. Complex., 26, 68-78, 2016. 